severe depression meant the person was by definition incapable; 38\% thought that a recent assessment of incapacity meant the person was by definition incapable, but this is wrong as a capacity assessment is only valid for a specific question at a specific point in time. No completed questionnaire had all the answers correct.

With the full implementation of the Mental Capacity Act 2005 fast approaching this shows a great need for teaching and guidance on capacity.

CHRIS SCHOFIELD

Specialist Registrar Liaison Psychiatry Queens Medical Centre, Nottingham

\section{Napoleon's doctors}

Editor - I read the book review on Napoleon's Doctors with interest. I imagine that members of my Society would be happy to claim the victory at Waterloo for Admiral Lord Nelson and although he had been dead for 10 years, perhaps his influence came from above. The two great men, Nelson and Wellington, met only once, fleetingly, at the Colonial Office on 12 September 1805. Thirty years later, by now Prime Minister, Wellington said 'I don't know that I ever had a conversation that interested me more'.

JK WOOD

Vice Chairman The Nelson Society

While grateful for the suggestion of divine intervention it was more likely a failure on the part of the Editor to spot this error. Napoleon was of course defeated at Waterloo by the Duke of Wellington (and not by Nelson who died in 1805, ten years before the battle).

Editor

\section{Myths of ageing}

Editor - Mulley's lecture (Clin Med January/ February 2007 pp 68-72) is very thoughtprovoking and raises a number of important issues concerning the negative stereotyping of older people. There is, however, another type of false reasoning about the elderly which is widespread, namely the notion that it is unnecessary to even consider a patient's age when making decisions about their treatment: some older people (and their relatives) are hopelessly unrealistic about the likely benefits of treatment, especially advanced, technologically intensive treatment, in people of advanced age. I recently had a conversation with the next of kin of a patient who was in his mid-80s. He had chronic renal failure and aortic stenosis and was not responding to treatment for pneumonia. Despite the patient's history and poor clinical condition I found it very difficult to persuade the relative that continuation of active treatment was unlikely to be of benefit.

Whether we like it or not, advancing age is a proxy for progressive loss of functional reserve in vital organs, and usually in several organs rather than just one. If one adds to this the stress of an acute illness (pneumonia, myocardial infarction or whatever) then it is no surprise if things do not go well. The able physician, it seems to me, is the one who can give proper weight to the patient's age in the overall assessment of their condition and medical prognosis. Mulley has, rightly, reminded us of the serious dangers of jumping to negative conclusions when looking after older people. I would venture to ask him also to be aware of the risk of exposing doctors to criticism (especially from patients' families) for simply attempting to make a balanced judgement about the care of older patients.

ROGER A FISKEN Consultant Physician Friarage Hospital, Northallerton

\section{Modern management of atrial fibrillation}

Editor - The reluctance to anticoagulate elderly patients with atrial fibrillation (AF) (Clin Med January/February 2007 pp 28-34), even in the absence of contraindications, ${ }^{1}$ might, at least in part, be attributable to the fear that, in the event of treatment-related haemorrhagic complications, those patients might, by virtue of age alone, be denied life-saving interventional treatment. Already, it is acknowledged that as many as $46-48 \%$ of doctors, ranging from primary care to secondary care, would be prepared to deny patients aged $>65$ treatment that they would otherwise offer to their younger counterparts. ${ }^{2}$ These attitudes are exemplified by the proposal (unsupported by any prospective study) that, following traumatic intracranial haematoma (typically a subdural haematoma resulting from 'a tumble downstairs $^{3}$ ) 'there is little point in active treatment over the age of 65 for those who remain in coma (Glasgow coma scale of 8 or less) for more than $6 \mathrm{~h} . . .{ }^{3}$ Furthermore, patients aged 65 or more with either extradural or acute subdural haematoma are less likely to be transferred to neurosurgical care than their younger counterparts. ${ }^{4}$ With regard to upper gastrointestinal haemorrhage, although an audit of patients with bleeding peptic ulcer documented a reduction in mortality if the over 60 s were operated on early, ${ }^{5}$ this does not necessarily translate into a more proactively interventional stance for the over $65 \mathrm{~s}$ and over $75 \mathrm{~s}$ with this complication, given the recent findings on doctors' ageist attitudes. $^{2}$ In the final analysis, it is our uncertainty about the attitudes of our colleagues which generates a reluctance to prescribe anticoagulants to the over $65 \mathrm{~s}$.

OMP JOLOBE

Retired Geriatrician Didsbury, Manchester

\section{References}

1 Friberg L, Hammar N, Ringh M, Petterson $\mathrm{H}$, Rosenqvist M. Stroke prophylaxis in atrial fibrillation: who gets it and who does not? Eur Heart J 2006:27:1954-64.

2 Harries C, Forrest D, Harvey N, McClelland A, Bowling A. Which doctors are influenced by a patient's age? A multimethod study of angina treatment in general practice, cardiology, and gerontology. Qual Saf Health Care 2007:16:23-7.

3 Maurice-Williams RS. Head injuries in the elderly. Br J Neurosurg 1999:13:5-8.

4 Munro PT, Smith RD, Parke TR. Effect of patients' age on management of acute intracranial haematoma: a prospective national study. BMJ 2002:325:1001-3.

5 Wheatley KE, Snyman JH, Brearley S et al. Mortality in patients with bleeding ulcer when those aged 60 or over are operated on early. BMJ 1990:301:272.

\section{In response}

It is with interest that we read comments raising the possibility that the ageist attitudes of physicians is the primary factor responsible for the under-prescribing of anticoagulation in those at greatest risk of 